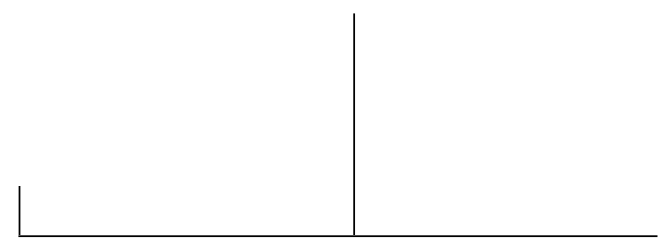

Rev. Latinoam. Psicopat. Fund., São Paulo, v. 15, n. 4, p. 812-824, dezembro 2012

\title{
Intermitências no cotidiano: criação e resistência na clínica*
}

Mário Francis Petry Londero

Simone Mainieri Paulon

Este artigo discute o ato criativo na clínica como forma de resistência a um cotidiano que pode endurecer as relações que estão em jogo no clinicar. A cartografia sustenta metodologicamente este relato de experiência realizado em encontros clínicos, tomando o território clínico no que ele tem de problemático a partir de uma trajetória de acompanhamento terapêutico. A condição para uma clínica inventiva está em sua aposta de estremecer mundo e sujeito no que eles têm de singular, assim como imprimir deslocamentos em si mesma diante do inusitado.

Palavras-chave: Clínica, acompanhamento terapêutico, ato criativo, cotidiano

*Este artigo foi parte do desenvolvimento dos estudos no mestrado acadêmico de Mário Francis Petry Londero, orientado pela professora doutora Simone Mainieri Paulon. 


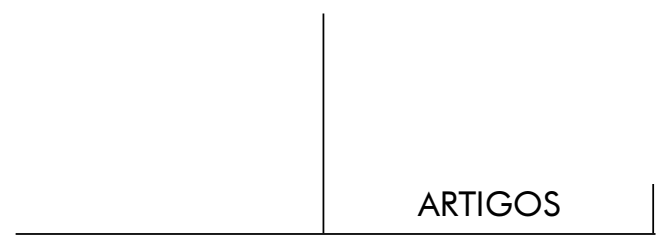

\section{Introdução}

Este artigo propõe uma discussão sobre o ato criativo na clínica, tomando o território clínico no que ele tem de problemático a partir de uma trajetória de acompanhamento terapêutico (A.T.). Anunciamos de saída que falamos de uma clínica em composição, ao inventar-se com os múltiplos fatores que a atravessam no estar se fazendo com o mundo. Nesse caso, o plano da clínica se torna híbrido e transdisciplinar, operando sempre num certo limiar que a define e que a transborda, espécie de "entre-dois" no qual "a clínica se apresenta como experiência que não pode realizar-se senão neste plano em que os domínios do eu e do outro, do si e do mundo, do clínico e do não clínico se transversalizam" (Passos \& Barros, 2004, p. 279).

A produção cartográfica entra em jogo para dar sustentação metodológica a este relato de experiência clínica retirado de encontros de A.T. que se passaram dentro de um hospital. Explora, para tanto, os mapas afetivos em seus trajetos dinâmicos que perpassam a clínica traçada pela intervenção em foco. Constitui-se, assim, numa reflexão acerca de um fazer clínico que permita passagens ao produzir subjetividades que destoam do que até então se fazia presente entre os transeuntes do asséptico meio hospitalar e o próprio meio em que se intervinha.

\section{O ato criativo como fazer clínico}

A "utopia" nos inspira "a não deixarmos de caminhar" (Galeano, 2007 , p. 57) ao expressar sua recusa em relação a uma vida espremida pelas possibilidades de um cotidiano arrastado. Ao caminharmos, apontamos para um sempre desigual, numa deformidade junto ao cotidiano posto e visto como único provável. É a um, dois ou mais passos à frente do atual que a utopia se encontra, sempre num impensável porvir. A utopia, de certa maneira, instala uma dúvida sobre o horizonte definido enquanto caminho a percorrer por determinada sociedade. 
Pelbart (2010), ao pensar junto a Deleuze o conceito de utopia, sinaliza que o mesmo se passa ao "liberar a imanência de todos os limites que o capital lhe impõe, o qual jamais remete a uma forma ideal. Designa, pois, o encontro entre um movimento infinito e o que há de real aqui e agora" (p. 14). Em sintonia com os filósofos, é possível trazer da gênese grega o termo utopia descrevendo-o como "um sistema social que ainda não existe em nenhum lugar e que, portanto, está em contradição com a ordem existente" (Löwy, 1988, p. 14). É o atual sendo problematizado pelo plano virtual que traz à tona a caduquice que se produziria no cotidiano caso ficasse isolado em uma direção reta e sem percalços. Complementando essa ideia: “... o virtual é o que existe em potência e não em ato. O virtual tende a atualizar-se", ou seja, a "atualização aparece como a solução de um problema" (Levy, 1996, p. 17).

O mergulho num ato utópico inquieta, pois violenta as rotinas dadas em seus circuitos fechados num amanhã já programado. Contradiz uma ordem vigente à medida que inventa "novas imagens de mundo questionando a paralisia das imagens estagnadas às quais nos habituamos" (Sousa, 2009, p. 66). Um outro mundo possível desenha-se por esta via que correlaciona o termo utopia ao ato de criação, no que incidem junto ao cotidiano de maneira a tensioná-lo. ${ }^{1}$ Faz-se necessário explorar um pouco mais a potência do ato criativo advindo do plano da arte em seu agenciamento com uma clínica que se proponha a efetivar "descontinuidades" sobre uma "imagem do amanhã" (Sousa, 2008, p. 11) trancafiada pela previsibilidade.

O que seria um ato criativo? Na clínica e em seus movimentos onde esse ato se faria presente? Qual a ligação existente entre o ato criativo e uma possível resistência sobre o que se encontra cotidianizado? Partindo-se de uma compreensão de que o ato criativo está próximo ao que um artista produz em determinada obra de arte, caberiam, ainda, as perguntas: Seria a arte uma habilidade? Um efeito estético posto? Uma técnica? Mas, que habilidade ou técnica seria essa? Será a de viver a vida? E criação, o que seria? Pois bem, criação pode significar a instauração de ações-obras. Visto assim, o artista seria alguém que está a produzir em ato, criando por meio de suas habilidades, brechas em si e, por consequência, no mundo que o cerca. $\mathrm{O}$ ato criativo acaba por elevar-se como instrumento criador de ações desestabilizadoras ao longo da vida. É um gesto de criar a própria vida e, assim, efetivar novas possibilidades ao operar descontinuidades na mesma.

\footnotetext{
${ }^{1}$ Apesar desse verbo não constar no dicionário, no presente artigo ele está se referindo ao sentido advindo de tensão, diferente de tencionar que significa projetar, planejar, ter a intenção de.
} 


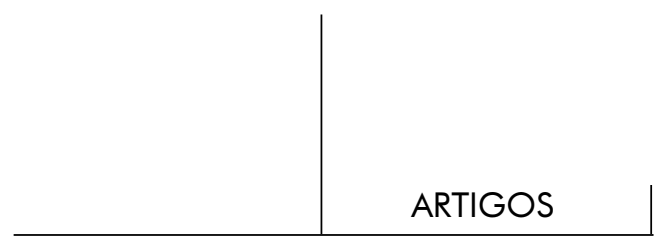

Destarte, a arte em sua produção tem em si a potência do ato criativo puro, ela se faz enquanto processo de desestabilização do que até certo momento se encontrava estagnado. Uma clínica em enlace com o ato criativo faz borda com a arte em toda a sua potência de composição estética, completamente diferente de qualquer outra composição existente:

Composição, composição, eis a única definição da arte. A composição estética, e o que não é composto não é uma obra de arte. Não confundiremos todavia a composição técnica, trabalho do material que faz frequentemente intervir a ciência (matemática, física, química, anatomia) e a composição estética, que é o trabalho da sensação. Só este último merece plenamente o nome de composição, e nunca uma obra de arte é feita por técnica ou pela técnica. (Deleuze \& Guattari, 1992, p. 247)

O processo de análise clínica se passa dessa maneira no plano de composição próprio da arte e das sensações que são disparadas em seu momento sublime de criação. Potência inventiva que desliza pelas composições criativas e que imprime resistência perante um modus operandi por demais burocratizado. Justamente por isso, é um fazer-se obra de arte que está em jogo no trabalho clínico, acompanhando cada movimento, cada relação de forças que atravessam o seu fazer a fim de afirmar a produção estética. A clínica ganha uma perspectiva inventiva em sua condição de interferência junto aos lugares em que imprime sua escuta.

Nesse sentido, a clínica se faz em suas andanças, é "peripatética" ao "passear, ir e vir conversando" (Lancetti, 2007, p. 15) e se criando em seu caminhar sempre em composição. Com essa atribuição nômade, tal como nos gregos, produzida por meio de livres caminhadas pelo pensamento, é que a clínica ganha sustentação ao abarcar em si uma modalidade clínica conhecida como A.T. Trazendo elementos potentes do andar pela cidade, o A.T. produz interferências junto aos territórios já demarcados e constituídos. Nessa prática, acompanhante e acompanhado irrompem nos lugares postos, provocando desvios às paisagens que ali se encontravam sobrepostas. Paisagens subjetivas no entre que perpassa os lugares, o acompanhante e o acompanhado, num confrontar-se "com uma multiplicidade de cartografias que darão aos Agenciamentos de subjetivação seu regime" (Guattari, 1992, p. 22). Tal acompanhar cartográfico da prática do A.T. se passa numa abertura "aos múltiplos territórios que se intercruzam na cidade, na experiência suscitada pelo acompanhamento terapêutico que desvela a possibilidade de operar a clínica nesse registro em que a guerra, a conflitualidade, o imprevisto têm lugar" (Palombini, 2006, p. 126).

É interessante ver o quanto esse setting aberto convida a rupturas junto a uma clínica feita entre quatro paredes, que dificulta ou mesmo inviabiliza um 
trânsito maior pelo inusitado, a não ser que tal prática clínica agencie em si a força do inesperado. Nessa clínica já engessada, os lugares e as ações estão postos, sobrecodificados, bastando ao analista e ao analisante tomarem posse de suas identidades demarcadas que deixam pouca abertura para a emergência de um desigual. Já a clínica do A.T., ao embaralhar os lugares/papéis previamente instituídos, opera uma mistura que abre brechas a uma invenção relacional até então impensável à ortodoxia terapêutica. Ou seja, se produz um "deslocamento para a fronteira", no qual entram em "jogo muitos ambientes que não costumavam integrar o território clínico" (Rolnik, 1997, p. 86).

As paisagens afetivas que perpassam tal clínica contaminada pelas andanças se confrontam, convocando os entrelugares do cotidiano - como a rua, a praça, o hospital, a casa - a interagirem e efetivarem deslocamentos nas rotas dadas. É uma constante criação da atmosfera do setting independente do lugar em que ocorra. Importa é disparar uma transformação das paisagens que são atingidas nessa interferência que não abrange mais somente analista e analisante, mas, sim, todo um universo que se conecta com a cena terapêutica. Nesse sentido, "o setting é a montagem, o cenário ou a situação; espaço dentro-fora facilitador da comunicação inconsciente-inconsciente; relação na qual o psicanalista opera" (Lancetti, 2007, p. 20), numa confabulação no entre das paisagens subjetivas que interagem na vida como ela é.

Assim, a clínica, envolvida por todas as camadas de seu amplo espectro, implica um sofrer junto às ações transformadoras que nela são processadas, a saber, se instala na eminência do criar sentidos para o que se situava num processo de desatualização. Uma possível ética clínica, assim compreendida, torna essencial o acolher de qualquer tipo de sofrimento que ali se processe, com os quais o clínico se vê perpassado por milhares de possíveis existências diferentes das suas. Isso lhe coloca em uma posição limítrofe enquanto fragilidade para estar se desamparando à medida que põe seu corpo a disposição de paisagens diferentes daquelas a que já estava habituado em seu próprio cotidiano.

O analista e sua clínica, em certo sentido, padecem com a pessoa em análise, numa imersão junto ao sofrimento que se está tentando transpor. Há um correlacionar-se entre os processos afetivos do par analista-analisante. Faz-se importante na trajetória clínica o desenrolar dos afetos do próprio analista, já que somente assim se poderia ter um "encontro autêntico" (Kupermann, 2003) e potente em invenção. Esse psicanalista ainda destaca ao comentar a obra de Ferenczi:

Ferenczi acreditava que a libido do psicanalista tinha um papel crucial na promoção do acontecimento clínico, e que o trabalho de análise só poderia ocorrer se promovesse um autêntico encontro de afetos, o que propiciaria o "diálo- 


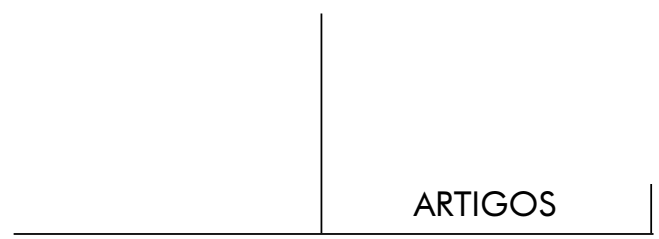

go de inconscientes", para o qual o psicanalista deveria comparecer de corpo presente. (p. 49)

Nessa abertura de corpo para o outro, o analista é demandado a se reinventar para dar conta dessa fragilidade relacional que a clínica exige. Dispor, todavia, o corpo a este diálogo de inconscientes, não é um processo indolor, pois a "dor é vida exacerbada. O processo dói. É o espreguiçamento amplo até onde a pessoa pode se esticar" (Lispector, 1973, p. 75). Dessa forma, o processo clínico se dá em passagem/composição, no exacerbamento das relações, em seus deslocamentos que proporcionam o caducar da velha noção de neutralidade, na qual o analista se colocava numa posição de não relação. Se entendemos que é exatamente no encontro entre corpos, na relação em ato, que o analista se coloca como corpo afetivo - e não como espelho reduzido a refletir sempre a mesma imagem parental atualizada na transferência - é nessa relação mesma que podemos vislumbrar a criação constante do fazer clínico. Nesse ponto de inflexão entre os afetos do analista e do analisante é que a clínica se apresenta como um acompanhar afetivo que "permite ressignificar a existência do sujeito em análise; criando modos de subjetivação inéditos" (Kupermann, 2003, p. 55).

Na mesma medida, aquele que procura a clínica em razão de um sofrimento, se transforma a partir da relação entre afetos que o espaço clínico deflagra. Movimentos de corpos, pausas, ritmos que vão se criando ao se articularem de maneira cada vez mais próxima até o instante no qual a mistura dos corpos expresse um acoplamento que produz uma indistinção entre um e outro corpo em seu momento de vir a ser. Rachaduras se criam, brechas que se anunciam diante desse instante fora do tempo/espaço que o encontro-acontecimento reverbera numa relação que nasce para se diferenciar do que até então estava posto. É o acontecimento como ferramenta clínica de "atualização e porvir, mas também de desatualização do hoje" (Cardoso, 1995, p. 56) no que ele traz de previsibilidade para o viver.

A clínica, nessa perspectiva, é produzida fio-a-fio entre aqueles que estão envolvidos - singular a cada encontro. Cria-se, então, a atmosfera do setting na confabulação que se passa no entre das paisagens subjetivas que interagem. Sua prática situa-se na experimentação das relações que se põem em jogo no processo clínico. Ao clínico, assim entendido, caberia "acompanhar o desdobrar das criações que surgem nos encontros", sendo que seu corpo necessita "estar aberto, precisando ser permeável a essas virtualidades que a todo o tempo o atravessam" (Araújo, 2007, p. 94).

Observamos essa trama clínica a partir de um A.T. realizado com uma criança internada num hospital. O desafio era o de transpor o espaço demasiadamente hospitalar para nele emergir um clinicar que produzisse passagens. A ideia era 
instalar desvios dentro de um ambiente extremamente duro em sua lógica de cuidado, transformando inclusive os sentidos que a clínica ali recebia. Assim, em visitas semanais, o menino era acompanhado naquele espaço nada receptivo para crianças: cotidianizado pelas regras adultas de variados cuidados em relação ao silêncio, as contaminações e quaisquer ações que saíssem do programado nos protocolos hospitalares.

No andar em que se encontrava, existia a hora da recreação, no entanto, isso durava até as cinco e meia da tarde. Depois disso, porém, o que aquelas crianças com os mais variados sofrimentos poderiam fazer com sua sede de brincar? Ainda mais se tratando de um "menino selvagem" em função de sua agitação e agressividade. Ao ser internado diversas vezes para fins de testagens medicamentosas - visando o controle de seus impulsos agressivos - acabava por perder seu chão de maneira abrupta, o que, invariavelmente, acarretava na piora de seu sintoma de hostilidade, tanto nos momentos em que se encontrava em casa quanto nos períodos de internação.

Isso, obviamente, reafirmava a necessidade de internações cada vez mais assíduas e prolongadas, já que, na maioria das vezes, os profissionais que o cuidavam no hospital não compreendiam muito bem sua singularidade e tampouco se subsidiavam com relatos de quem o atendia fora do hospital. Nosso menino, então, cada vez mais sucumbia à taxativa designação de "selvagem-incurável" que lhe fora atribuída: 'um estranho no ninho!' Essa situação chegou a um limite que já não conseguia mais fazer nem de seu ambiente familiar seu chão.

Justifica-se aí a entrada em cena do A.T., inicialmente com a simples incumbência de acalmar o menino nos períodos de internação, ao menos por algumas horas, para que o setor em que se encontrava descansasse um pouco. Entendíamos, entretanto, que a produção clínica do A.T., mesmo no ambiente hospitalar, poderia ser bem mais do que apenas uma medida paliativa, mais do que uma espécie de alívio como um medicamento tranquilizador. A compreensão do A.T. como uma ampliação da clínica que também extrapola o setting, permitia-nos vislumbrar ali um movimento de construção de um espaço familiar na criação de um novo chão para esse menino que sofria junto àqueles que o cuidavam na internação. Pela mesma via, abria-se a perspectiva de mostrar aos cuidadores do garoto o quanto ele era capaz de se relacionar com um outro sem necessitar recorrer às agressões - sua ferramenta de defesa tão utilizada quando se sentia rejeitado.

A partir daí, A.T. e menino demarcavam as goleiras do seu futebol ao cair da tarde, momento em que aparentemente nada acontecia nesta unidade hospitalar.

${ }^{2}$ Apelido dado pelos cuidadores do hospital.

Rev. Latinoam. Psicopat. Fund., São Paulo, v. 15, n. 4, p. 812-824, dezembro 2012 


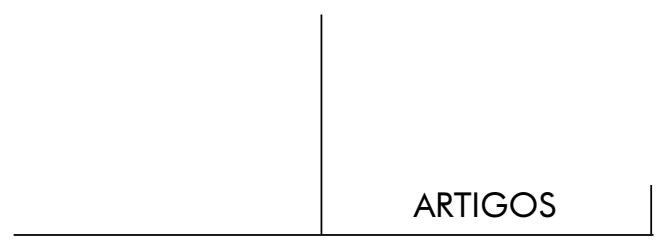

Era a hora das visitas se retirarem e dos recreacionistas descansarem, deixando os espaços livres apenas para circulação dos médicos e enfermeiros com seus passos pesados demais para acompanhar as crianças. Passos acostumados ao tempo da concretude das urgências hospitalares! Contrariando o fluxo dos afetos assépticos que o hospital emanava, A.T. e menino inventavam um espaço para correrias, brincadeiras e risadas num jogo fortemente disputado. O desafio era transformar corredores silenciosos e friamente habitados num espaço para o suor, gritos e choques entre corpos. Ali, a estranha dupla fazia com que as forças, até então circulantes no andar, se deslocassem.

Acompanhante e acompanhado passaram, assim, a habitar o corredor próximo aos elevadores e escadaria correndo de um lado para o outro em busca do gol. Por vezes, faziam-se acompanhar de outras crianças, parentes ou profissionais em busca de preencherem, também, seus espaços-tempos vazios; em outros momentos simplesmente realizavam sua disputa a dois. Pouco importava a quantidade de jogadores que angariassem, pois, o interessante era a interferência que permitia uma dissonância no costumeiro que imperava pelos corredores e que tanto angustiava aquele menino com ares de selvagem engavetado pelas regras dispostas na internação. Era um momento que servia para que ele esquecesse onde estava, aproveitando para fazer algo que adorava, isto é, jogar bola. "Assim, forjou-se um tempo no qual era possível encontrar expressões para as agonias impensáveis e fazê-las circular" (Aragon, 2007, p. 145). Instantes que, tanto o menino quanto o corredor hospitalar, se transmutavam junto ao trabalho clínico ali proposto, formando uma espécie de passagem entre as paisagens que estavam postas rumo a um ambiente propício para o inusitado. Nessa deriva do acompanhar clínico, "o sentido que surge das passagens faz com que esses passeios façam diferença" (Araújo, 2007, p. 51).

Os transeuntes que por ali passavam tentavam desviar, saíam apressados e se surpreendiam com aquilo que acontecia dentro do hospital. Surpreendiam-se, também, com aquele garoto que na maioria das vezes viam agredir os trabalhadores e as outras crianças internadas e que, naquele meio tempo, ficava amistoso e convidativo para a disputa futebolística. Olhavam, estranhavam e, na maioria das vezes, voltavam à normalidade dos passos determinados e sem pensamentos pelos corredores. Coisa inusitada ali se fazia, num cotidiano em vias de desvio de sua rota normativa, marcando àqueles que por ali passavam e que até então não viam nada além de um corredor sem fundo e um "menino selvagem". A prática clínica alicerçada pelo A.T. parece promover uma espécie de colisão inventiva sobre os sentidos postos:

Pois é acompanhando a pessoa em seu passeio que acompanhamos também o surgimento do sentido, e mais fundamentalmente, as mudanças de sentido. $\mathrm{O}$ 
advento do sentido através do passeio entre as coisas, todavia também um passeio entre os sentidos, já que eles não são estáticos. (Ibid., p. 51)

Não que se operassem milagres entre aqueles que passavam pelo estranho setting-corredor-campo de futebol. Contudo, tanto o A.T. como o garotinho sentiam o contágio que produziam, ao eventualmente conquistarem a empatia de alguns profissionais que se animavam perante as partidas e passavam a se dispor a uma outra relação com o menino. Da mesma forma, aquele espaço propiciava um ambiente mais saudável para nosso "selvagem" junto às outras crianças, com as quais - via futebol - construía uma amizade menos desconfiada e favorável a novos encontros. O A.T., nesse caso, foi uma espécie de facilitador para a vigoração do acompanhado a partir de ensaios que se inventavam no decorrer dos encontros hospitalares. Um vigor no sentido de possibilitar um chão, num contato mais acolhedor entre o garoto junto ao entorno hospitalar que até então lhe parecera tão hostil.

A clínica se desdobra, inventa settings-corredores, põe a correr assepsias naturalizadas no cotidiano hospitalar, estabelece o "compromisso com os movimentos que a vida faz na tentativa de encontrar vias de afirmação criadora" (Rolnik, 1997, p. 94) ao produzir uma escuta ativa que vai ao encontro do que a pessoa em padecimento necessita. Bem mais que isso, a clínica é envolvida pela construção operada pela dupla que está a forjar um ambiente para atos criativos, "apreendendo a problemática singular que se coloca no contexto no qual é chamada a intervir" (ibid.).

A clínica contaminada pela ética nômade do A.T. conecta-se à ideia de fazer resistência numa política da invenção perante um socius burocratizador. Contraria, assim, uma clínica adaptativa que eliminaria as arestas supostamente negativas do sujeito em relação ao mundo, sujeitando-o a uma ordem seletiva que produz sofrimento em seus mecanismos de controle e exclusão. A condição para uma clínica inventiva, tal como aqui se enuncia, está, justamente, em sua aposta de estremecer o mundo e o sujeito no que eles têm de singular, assim como em imprimir deslocamentos em si mesma diante do inesperado que cada relação clínica oferta. Dessa maneira, os atos criativos no clinicar propiciam brechas, deformações nas formas que ditam até onde poderíamos contornar o viver. $\mathrm{O}$ inusitado pede passagem neste jogo de forças, permite existências singulares que resistem ao cotidianizar-se: resistência enquanto ato criativo! Eis um movimento que perfura o cotidiano, deforma-o no que em si há de controle, viabilizando, no seio burocrático apaziguador que nos anestesia e faz a vida minguar, a presença de uma espécie de estesia, uma sensibilidade que nos atira para a experimentação de outros sentidos. 


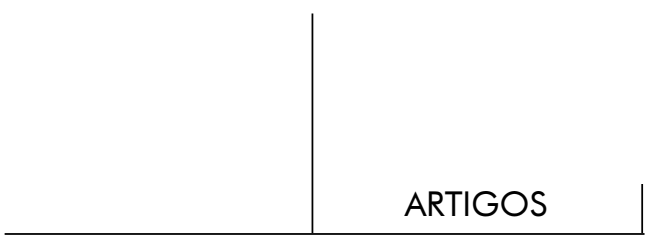

A clínica sem fim

O escrito aqui apresentado teve a intenção de tensionar o fazer clínico ao produzir outros caminhos, percursos inusitados que ampliassem o olhar sobre a clínica em constante construção. Para pensá-la, valemo-nos do relato da experiência clínica de A.T. feita dentro de um hospital com sua respectiva trama, que apresenta o encontro clínico enquanto resistência à normatização do cotidiano à medida que entra em composição com o plano da arte em sua potência inventiva de destoar da previsibilidade do que está posto como regra.

Diante do percurso transcorrido nessas páginas, chegamos ao seu final sem a pretensão de dar maiores respostas à problematização aqui exposta em relação à clínica em seu potencial de criação. Viajamos sobre as planícies do fazer clínico, deslocando-nos para outros possíveis, margeando essa tendência para ser a seguir outra coisa num ato de desassossego inventivo. A inspiração é na poética pessoniana, já que a "essência de haver um problema é não haver uma solução" para, assim, existir sempre o potencial de se estar em invenção, em movimento, ao contrário de um solucionar paralisante (Pessoa, 2006, p. 134).

Agradecimentos: À Capes pelo incentivo financeiro fornecido no decorrer do mestrado.

\section{Referências}

Aragon, L. E. P. (2007). O impensável na clínica: virtualidades nos encontros clínicos. Porto Alegre: Sulina, Editora da UFRGS. (Coleção Cartografias).

Araújo, F. (2007). Um passeio esquizo pelo acompanhamento terapêutico: dos especialismos à política da amizade. Dissertação de mestrado em Estudos da Subjetividade, Universidade Federal Fluminense, Niterói.

Cardoso, I. de A. R. (1995 outubro). Foucault e a noção de acontecimento. Tempo Social. 7(1-2), 53-66.

Deleuze, G. \& Guattari, F. (1992). O que é a filosofia? (Bento Prado Júnior e Alberto Alonso Muñoz, trad.). Rio de Janeiro: Editora 34.

Galeano, E. (2007). As palavras andantes. (Eric Nepomuceno, trad.). [S.I.]: Ed. L\&PM.

Guattari, F. (1992). Caosmose: um novo paradigma estético (Ana Lúcia de Oliveira e Lúcia Cláudia Leão, trad.). São Paulo: Editora 34.

Kupermann, D. (2003 abril). A libido e o álibi do psicanalista: uma incursão pelo Diário Clínico de Ferenczi. Pulsional - Revista de psicanálise, XVI(168), 47-57. 
Lancetti, A. (2007). Clínica peripatética. São Paulo: Hucitec. (SaúdeLoucura; 20. Série Políticas do desejo; 1).

Levy, P. (1996). O que é o virtual? (Paulo Neves, trad.) São Paulo: Editora 34.

Lispector, C. (1973). Água viva. Rio de Janeiro: Círculo do Livro.

Löwy, M. (1988). Ideologias e ciência social: elementos para uma análise marxista (4 ed.). São Paulo: Cortez.

Palombini, A. de L. (2006). Acompanhamento terapêutico: dispositivo clínico-político. Psyche, 10(18), setembro. Recuperado em 19 fevereiro 2011 do http:// pepsic.homolog.bvsalud.org/scielo.php?script=sci_arttext\&pid=S1415$11382006000200012 \& \operatorname{lng}=$ pt\&nrm=iso.

Passos, E. \& Barros, R. B. (2004). O que pode a clínica? A posição de um problema e de um paradoxo. In Fonseca \& Engelman (Org.). Corpo, arte e clínica (Vol. 1, pp. 275-286). Porto Alegre: Ed. da Universidade Federal do Rio Grande do Sul.

Pelbart, P. P. (2010). A utopia imanente. DOSSIÊ CULT: Filosofia Francesa Contemporânea, edição especial (pp. 13-16), janeiro.

Pessoa, F. (2006). Livro do desassossego: composto por Bernardo Soares, ajudante de guarda-livros na cidade de Lisboa. R. Zenith (Org.). São Paulo: Companhia das Letras.

Rolnik, S. (1997). Clínica nômade. In Equipe de Acompanhantes Terapêuticos do Instituto A Casa (Orgs.), Crise e cidade: acompanhamento terapêutico. São Paulo: Educ.

Sousa, E. L. A. de (2008). A burocratização do amanhã: utopia e ato criativo. Porto Alegre (UFRGS), 24, 41-51.

Sousa, E. L. A. de \& Endo, P. (2009). Sigmund Freud: ciência, arte e política. Porto Alegre: L\&PM.

\section{Resumos}

(Intermittences in everyday life: creation and resistance in the clinic)

Creative acts in clinical work are discussed as forms of resistance to everyday life that can harden the relationship in a clinical setting. Cartography methodologically backs up this account of experiences had in clinical encounters, observing clinical work in one of its most problematic aspects, namely, therapeutic accompaniment. Conditions for clinical inventions are based on their double objective: 1) to shake up the subject and his or her world in their singularity, and, 2) to bring about dislocations in the clinical work when one is faced with the unexpected.

Key words: Clinic, therapeutic accompaniment, creative act, everyday life 
(Intermittences au quotidien: création et résistance en clinique)

Cet article discute l'acte créatif dans la clinique comme forme de résistance à un quotidien qui est susceptible de durcir les rapports en jeu dans la pratique clinique. La cartographie soutient méthodologiquement ce récit d'expériences vécues pendant des séances cliniques et les problèmes du domaine clinique sont analysés à partir du déroulement de l'accompagnement thérapeutique. Les conditions d'une clinique inventive se situent dans son effort de bouleverser le monde et le sujet dans ce qu'ils ont de singulier, ainsi que de provoquer des changements en soi-même face à l'insolite.

Mots clés: Clinique, accompagnement thérapeutique, acte crétif, quotidien

(Intermitencias en el cotidiano: creación y resistencia en la clínica)

Este artículo discute el acto creativo en la clínica como forma de resistencia a un cotidiano que puede endurecer las relaciones que se juegan en el acto clínico. La cartografía sostiene metodológicamente este relato de experiencia realizado en encuentros clínicos, tomando el territorio clínico en lo que tiene de problemáticas a partir de la trayectoria de un acompañamiento terapéutico. La condición para una clínica inventiva está en su apuesta de sacudir el mundo y el sujeto en lo que tienen de singular, así como imprimir desplazamientos en sí misma frente a lo inusitado.

Palabras claves: Clínica, acompañamiento terapéutico, acto creativo, cotidiano

(Intermittente Unterbrechungen im Alltag: Kreation und Widerstand in der Klinik)

In diesem Beitrag wird das kreative Handeln in der Klinik als Form des Widerstandes gegen den Alltag diskutiert, der die für die klinische Behandlung relevanten Beziehungen verhärten kann. Die Kartographie stützt diesen Erfahrungsbericht aus Begegnungen in der Klinik methodologisch, wobei der problematische Aspekt des klinischen Umfeldes ausgehend von der Vorgehensweise der therapeutischen Begleitung beleuchtet wird. Die Voraussetzung für die Schaffung einer schöpferischen klinischen Arbeit liegt in ihrer Absicht, die Welt und das Subjekt in ihrer Eigenart zu erschüttern. Dazu ist es nötig, die klinische Arbeit selbst zu verrücken.

Schlüsselwörter: Klinik, therapeutische Begleitung, kreativer Akt, Alltag

Citação/Citation: Londero, M. F. P. \& Paulon, S. M. (2012, dezembro). Intermitências no cotidiano: criação e resistência na clínica. Revista Latinoamericana de Psicopatologia Fundamental, 15(4), 812-824.

Editor do artigo/Editor: Prof. Dr. Manoel Tosta Berlinck

Recebido/Received: 24.7.2011 / 7.24.2011 Aceito/Accepted: 18.11.2011/11.18.2011

Rev. Latinoam. Psicopat. Fund., São Paulo, v. 15, n. 4, p. 812-824, dezembro 2012 
Copyright: () 2009 Associação Universitária de Pesquisa em Psicopatologia Fundamental/ University Association for Research in Fundamental Psychopathology. Este é um artigo de livre acesso, que permite uso irrestrito, distribuição e reprodução em qualquer meio, desde que o autor e a fonte sejam citados / This is an open-access article, which permits unrestricted use, distribution, and reproduction in any medium, provided the original author and source are credited.

Financiamento/Funding: Os autores declaram não ter sido financiados ou apoiados / The authors have no support or funding to report.

Conflito de interesses/Conflict of interest: Os autores declaram que não há conflito de interesses / The authors declare that has no conflict of interest.

\section{Mário Francis Petry Londero}

Mestre em Psicologia Social e Institucional pelo Programa de Pós-Graduação de Psicologia Social e Institucional - Universidade Federal do Rio Grande do Sul (Porto Alegre, RS, Br.).

Rua Marcílio Dias, 1487/5 -Bairro Menino Deus

90130-001 Porto Alegre, RS, Br.

Telefone: (51) 8522-2734

e-mail: francislonder@hotmail.com

\section{Simone Mainieri Paulon}

Doutora em Psicologia Clínica pela Pontifícia Universidade Católica de São Paulo - PUCSP (São Paulo, SP, Br.).

Rua Edmundo Gardolinski, 115 - Casa 4 - Bairro Boa Vista

90480-130 Porto Alegre, RS, Br.

Telefone: (51) 8418-8447

e-mail: simonepaulon@gmail.com 